\title{
WHERE HAVE YOUR TIME AND SPACE GONE? AN ANALYSIS OF TECHNOLOGY ADDICTION, SURVEILLANCE CAPITALISM, AND THE MODERN PANOPTICON
}

\author{
ERIKA MATSUI*
}

\begin{abstract}
Little attention has been paid to why individuals are addicted to Internet-related experiences. This research identifies a key driver of technology addiction by combining three perspectives: behavioural science, economics, and psychoanalysis. Behavioural science reveals that technology addiction is produced by well-designed technology that fulfils humans' fundamental needs. Capital economy analysis, called surveillance capitalism, offers a new interpretation of the data-driven economy, in which Internet technology enterprises collect feedback from users' experiences and use said feedback to improve their products. The data accumulation logic facilitates automatic thinking and the modification of users' behaviours to make a profit for the enterprises. Psychoanalysis clarifies the relationship between surveillance power and behavioural changes in society. The Panopticon, a central observation tower with a circle of prison cells, achieved an automatic function of power to control individuals' performances and minds. Technology addiction is a symptom of the modern Panopticon because a common mechanism works between the Panopticon and surveillance capitalism, occupying individuals' time and space and executing the automatic function of the surveillance power that facilitates behavioural modification. We conclude that depriving individuals of both time and space is a key driver of technology addiction that threatens sovereignty in a data-driven economy. We also provide three solutions to technology addiction: acknowledgement of the benefits and risks of technology use, acceptance of the complexity underlying technology-related issues, and protection of individual sovereignty.
\end{abstract}

Keywords: Technology addiction; Surveillance capitalism; Panopticon

\section{INTRODUCTION}

People in the twenty-first century cannot spend a day without digital technology that fulfils the human need for stimulation, communication, and environmental changes. Indeed, $59 \%$ of the global population (approximately 6.57 billion people) actively uses the Internet, and the average smartphone user spends 2 hours and 51 minutes on his device each day, touching his device about 2,617 times (Zuckerman 2020a; Zuckerman 2020b). The extreme use of technology hinders individuals' ability to resist checking, scrolling, and clicking on their phone. Technology addiction involves a loss of control over technology use, without regard to the negative consequences these reactions have on the individual or others. Psychological literature focuses on the negative impacts of technology addiction that interfere with work, education, family, social lives, and physical and emotional functioning (Block 2008; Das et al. 2017; Ferraro et al. 2007; Morahan-Martin \& Schumacher 2000; Turel, Serenko \& Giles, 2011). However, little research has identified a key driver of technology addiction from multiple perspectives. 
This research will explore what behavioural, economic, and psychological mechanisms exist behind technology addiction. Behavioural science focuses on the surprising causes and nature of technology addiction (Alter 2017), which enhances our understanding of why we experience an irresistible need to engage with technological devices in this global pandemic of technology addiction. Behavioural science, however, does not sufficiently explain the relationship between technology-addicted behaviours and the data-driven economy. Given that individual behaviours are embedded into economic activities in the global market, Internet users' behaviours may be promoted by Internet service providers. An economic perspective, such as surveillance capitalism, as proposed by Zuboff (2019), widens our views to understand what economical mechanism exists in the modern digital era. A new interpretation of the digital economy in the twenty-first century reveals that technological interventions, such as nudges, change individuals' behaviours, which finally makes profits for the digital service providers. The critical issue in the data-driven economy is the threat of individual sovereignty; Internet users are not aware of their behavioural modification while they use the technology services. This issue, however, has existed for a long time, and Michel Foucault, an advocate of surveillance study, analysed the mechanisms of surveillance power in the modern society. The interdisciplinary perspective of behavioural science, economics, and psychoanalysis will identify why we are addicted to technology and how we can mitigate its negative impacts while still receiving its tremendous benefits.

\section{METHODOLOGY}

This research used an interdisciplinary, qualitative inquiry approach, with a literature review in the fields of behavioural science, economics, and psychoanalysis. A qualitative inquiry offers new views and discoveries on phenomena when existing theory is insufficient or unable to explain said phenomena (Butler, O'Hare, Kestenbaum, Sayre, and Wong 2021). Specifically, an interdisciplinary, qualitative inquiry introduces new divisions of knowledge, building upon conventional and segregated divisions of knowledge in the social sciences, which are subjected to reform, reconstruction, and criticism in certain fields (Greckhamer et al. 2008). An interdisciplinary, qualitative inquiry, coupled with behavioural-economic-psychological perspectives, was employed to identify a key driver of technology-addicted behaviours in the surveillance capitalism economy. Firstly, this research adopted a behavioural science perspective to reveal a behavioural mechanism of technology addiction. Then, it used an economic perspective to find a new interpretation of capitalism by analysing Internet-related experiences in a data-driven economy. Finally, this research focused on psychological perspectives of surveillance power.

\section{RESULTS AND DISCUSSION}

\section{Behavioural Mechanism of Technology Addiction}

Behavioural science reveals a paradox between technology and human behaviours; Internet technology is compelling enough to be believed to effectively use time and space, yet users cannot resist spending several hours viewing a screen. Why does such a paradox occur? A leading factor of our experience is technology addiction, an unprecedented, global pandemic of addiction to screens (Alter 2017). Owing to the widespread use of the Internet, technologyaddicted behaviours have become more mainstream than before. Technology addiction involves a psychological dependence on the Internet, which is characterised by an excessive 
investment of resources on Internet-related experiences, negative feelings during offline time, and a high level of distress while waiting to be connected to the Internet (Potenza 2006). Researchers, educators, and mental health professionals should pay attention to technology addiction, which is just as important as substance addiction. Substance addiction, such as an addiction to alcohol or drugs, has existed for the past several centuries (Alter 2017; Maddux \& Desmond 2000; Potenza 2006). A critical difference between substance addiction and behavioural addiction is that behavioural addiction does not directly introduce chemicals into the body (Alter 2017). Nevertheless, behavioural addiction produces the same effects as dependence on a substance, and a loss of behavioural control eventually brings about significant difficulties in major personal domains, such as psychological health, interpersonal relationships, employment, and education (Alter 2017; Davis 2001; Potenza 2006; Shapira et al. 2000; Young 1998). This is because substance and behavioural addictions activate the same brain fields to fulfil the fundamental human needs for social participation, social support, mental simulation, and a sense of effectiveness (Alter 2017). We must not leap to the conclusion that we should avoid an excessive use of the Internet; indeed, there is debate whether it is appropriate to label an excessive use of the Internet as an addiction (Potenza 2006). Rather, we should investigate what aspects of digital technology meet humans' fundamental needs and what technological mechanism facilitates addicted behaviours.

Alter (2017) maintains that there are six elements of technology that hinder individuals' ability to resist using it: goals, feedback, progress, escalation, cliffhangers, and social interaction. These elements fulfil users' basic needs in many ways. Small and compelling goals, progress, and escalation meet the users' needs for effectiveness and mental simulation (i.e., the cognitive ability to imagine actions and the probable results). Goal setting in one's personal life is an efficient way to consider how to spend a limited amount of time and energy on a project, and individuals can easily manage overwhelming goals if the goals are broken into smaller ones (Alter 2017). Digital technology services provide small and compelling goals based on this nature of human behaviours (Alter 2017). A pitfall is that the goals in digital technology services are uninvited; technology users unintentionally pursue goals that digital service providers predetermine. For example, social media is designed to seek followers and likes when users sign up for an account (Alter 2017). While the number of followers and likes may not be a goal that users want to pursue, they have no choice but to accomplish the goal displayed on the screen. Some users may experience the pleasure of progress from accomplishing the goal, but a new goal appears when they reach the initial goals. In addition to the never-ending pursuit of goals, the escalation of difficulty hooks users (Alter 2017). Nintendo Tetris is an easy game at first, but the game gets more difficult when users progress to later stages (Alter 2017). This illustrates that continual progress and escalation of hardships endlessly stimulate users' mental need to solve a new challenge. A vicious combination of goals, progress, and escalation produces an addictive experience - in consequence, many users tend to spend far more time on social media services than they expect.

Moreover, positive feedback and strong social connection fulfil a fundamental need for social interaction. Humans are social beings who interact with others to collect feedback; importantly, individuals have a desire to perceive themselves as valuable, worthy, and good (Toma and Hancock 2013). This fundamental need is strengthened in a developmental process. Personal development from a younger age involves learning to receive as much feedback as possible from one's surroundings, and adults cannot stop this habit even after maturing (Alter 2017). Online social networking sites (SNSs) best fulfil the needs for social connection and feedback. It is well known that Facebook was the first social media site to introduce the like button, and similar functions of the like button have become popular in other social networking services (Alter 2017). The reason for the widespread use of SNSs is real-time, positive feedback that promotes interactive communication among users who seek social feedback. 
Some studies suggest that SNSs tap into the needs for social support and self-expression by offering a social platform in which users connect with others to share similar interests (Kuss \& Griffiths 2017; Riva, Wiederhold \& Cipresso 2016). Moreover, accumulating evidence shows some positive impacts of SNSs; positive feedback on posted content has positive associations with self-esteem and well-being and a negative association with loneliness (Bazarova et al. 2015; Burke, Marlow \& Lento 2010; Burrow \& Rainone 2016; Oh, Ozkaya \& LaRose 2014; Valkenburg, Peter \& Schouten 2006).

Despite the fact that SNSs seem to perfectly meet the needs for social connection, SNSs are notorious for providing meaningless feedback that facilitates users' sensitivity to negative information. Instagram users give likes and positive comments to one photo, and the feedback mechanism helps the users understand which photo is more valuable than others (Alter 2017). This social feedback mechanism, however, does not explain the meaning of the number of likes; consequently, some users may interpret this to mean that they are worth one hundred likes. The vague feedback mechanism strengthens the tendency for humans to adopt positive ideas about themselves rather than negative ones (Alter 2017). This strategy may be efficient to avoid negative self-esteem; however, Alter (2017) suggests that this causes a new dilemma, where users become overly sensitive to negative feedback. This is because a 'bad is stronger than good' principle is at play here. Truly, the psychological effect of a bad experience outweighs the psychological effect of a good experience. As a result, some users may ignore negative feedback to maintain their sense of self-worth and narcissism.

To sum up, the elements are well-designed so that Internet technology services attract many users by fulfilling humans' fundamental need for social interaction. Together, a set of small and compelling goals, a sense of progress, and escalation meet users' needs for effectiveness and mental simulation. Still, we should not overlook that these elements may result in a waste of time and efforts to achieve unnecessary goals. We also found that positive feedback and strong social connection meet the demands of social networking; however, the social feedback mechanism amplifies addictive behaviours of seeking positive feedback without paying attention to negative feedback from others. Behavioural science clarifies that an interplay between humans' fundamental needs and well-designed technology facilitates the consumption of users' time and effort, which eventually leads to technology-addicted behaviours. Yet, why do digital technology services need to attract so many users? What is the purpose of users' behavioural changes? We will further explore these questions from an economic perspective.

\section{Data-Driven Economy and Surveillance Capitalism}

The user experience in a data-driven economy can be a new resource in which capitalists invest money to make a profit. Users consume time and space to interact with Internet services, and the result of the interaction can be transformed into digital information. A new logic of data accumulation has radically altered twenty-first century capitalism. Zuboff (2019) argues that industrial capitalism in the twentieth century was driven by the continuous enlargement of the means of production. Industrial capitalism offered a belief that we should invest money in the production of goods and services to make more profits because mass production was thought to increase wealth. By contrast, surveillance capitalism in the twenty-first century is driven by the continuous enlargement of the means of behavioural modification in a digitally connected environment (Zuboff 2019). That is, Internet users' behavioural modification plays an important role in producing and improving goods and services in the digital economy market. The user experience in surveillance capitalism is regarded as a free resource that can be translated into behavioural data (Zuboff 2019). For example, Google is widely recognised as the pioneer of big data, and the company has collected users' data with a new logic of 
accumulation (Mayer-Schönberger \& Cukier 2013; Zuboff 2015). The data accumulation logic, for its part, shapes a behavioural value reinvestment cycle; users provide their behavioural data for the Big Tech companies, and the companies extract and analyse the data to improve the speed, accuracy, and relevance of their goods and services (Zuboff 2019).

The data accumulation logic appears to be efficient to build a win-win relationship between technology providers and their users. Yet, this produces surveillance power that influences humans' decision-making and behaviours. In a data-driven economy, users' most predictive behavioural data leads to profitable outcomes; therefore, users' behaviours are modified and shaped by technological intervention (Zuboff 2019). For instance, nudging is a popular intervention wherein Internet users are required to use their judgement in choice environments. Digital nudging involves user-interface factors that affect human behaviour in digital choice environments (Djurica \& Figl 2017). A recommender system, one of the examples of digital nudging, provides customised, nudge-based recommendations when a user purchases goods and services in an online shop. Nudges appear to be effective for users to make smart decisions because they reduce users' cognitive efforts to collect and compare all the information by facilitating an unconscious, rapid, and automatic cognitive processing (i.e., thinking, reasoning, decision-making, and judgement) (Djurica \& Figl 2017; Evans 2008). This heuristic approach, called a System 1 process, was coined by Kahneman and Frederick (2002). Yet, the overuse of nudges may deteriorate consciousness and deliberately hasten cognitive processing, thus hampering the ability to make thoughtful, rational decisions. This is called a System 2 process (Kahneman and Frederick 2002). The point here is that technology intervention predetermines users' behaviours, and the users unconsciously modify their behaviours based on automated and quick decisions rather than effortful and slow decisions. Finally, this increases automated behaviours in a data-driven economy. In fact, the goal of surveillance capitalism is not only to automate information flows but also to automate humans (Zuboff 2019). This is because automated thinking and behaviours are favourable for those who gain profits in surveillance capitalism. Who are the major beneficiaries in surveillance capitalism? The main customers in surveillance capitalism are enterprises that sustain their future in the market (Zuboff 2019). In other words, Internet users consume time and space not for themselves but for service providers.

Basically, surveillance capitalism offers new interpretations about contemporary capitalism in the digital era. Internet users' behavioural changes are designed to accumulate data and improve products, eventually resulting in a profit for enterprises. We discussed that the data accumulation logic produces surveillance power in the data-driven economy. Automated behaviours, stimulated by technological interventions, appear to be unique symptoms in the twenty-first century; however, we would argue that the fundamental mechanism underlying surveillance capitalism is not new because surveillance power and automatic human behaviours existed before the advancement of the Internet. We will further discuss the relationship between surveillance power and human behaviours from a psychoanalytic perspective, which helps identify a key driver of technology-addicted behaviours in surveillance capitalism.

\section{Psychoanalytic View of Surveillance Power}

Psychoanalysis made its crucial contribution to understanding how to discipline and control the individual. Michel Foucault, a distinctive figure in psychoanalysis and surveillance studies, put forward a lucid analysis of surveillance power in the disciplinary society. According to Foucault (1977), all institutions (such as prisons, schools, factories, and hospitals) share a common role in accommodating individuals in a certain time and location, and the individuals are required to behave in a particular manner. Foucault further suggests that surveillance power 
is intensively allocated to the abnormal individual to restrict her/him and change her/his behaviours for normalisation. His analysis indicates two points to understand the relationship between surveillance and individuals' behavioural changes.

Firstly, a judgement of normalisation exists everywhere in institutions, and it yields institutions' surveillance power and individuals' behavioural changes. For example, teachers educate students at schools, executives manage their employees at workplaces, and doctors provide medical advice for patients at hospitals. These behaviours are based on the institutional norms in a particular field of knowledge, and almost all individuals' aspects, including the body, mind, and attitudes, are subjected to alteration for this normalisation. What is the purpose of the normalisation? Why do institutions execute surveillance power for normalisation? Foucault analyses the composition of forces by observing the force of a troop, suggesting that normalisation occurs for economic reasons. For instance, the process of training, maintaining, and arming the troops makes each soldier useful, and it maximises both efficiency and benefits to the troops by achieving a specific result. Foucault's analysis indicates that normalisation and the modification of individual behaviours are effective ways to achieve specific goals of the whole entity. This power mechanism shares a common point in the data accumulation logic in surveillance capitalism; the data acculturation logic produces the norm of user behaviours, and the service users modify their behaviours to respond to the technological intervention, which eventually leads to a profit in the economy market.

Another implication is that surveillance and obedience are produced by individuals' careful time distribution and partitioned spaces. Foucault suggests that a Panopticon, a modern architectural building for prisoners, achieved the most effective way to control an individual's time and space. A Panopticon was inspired by the letters and architectural sketchings of Jeremy Bentham (1748-1832), an English social reformer (Elmer 2012). The building was a unique structure, with one central tower for a single security guard surrounded by many cells for inmates. The central tower was designed so that the inmates could not watch the inside of the central tower. A Panopticon increased the effectiveness of permanent surveillance because 'the inmate must never know whether he is being looked at any one moment; but he must be sure that he may always be so' (Foucault 1977, 201). That is, it does not matter who executes the surveillance power because the inmates in a cell look at a situation from the viewpoint of the surveillant. This perspective helps the inmates internalise surveillance power in their mind and body by sensing that they could be observed anytime and anywhere.

We would argue that a Panopticon has been revived in surveillance capitalism, although researchers in surveillance studies have lost their interest in using a Panopticon to understand the contemporary surveillance society in different models (Bauman 2000; Caluya 2010; Koskela 2003; Lyon 2001; Norris \& Armstrong 1999; Poster 1990). Occupying digital service users' time and space executes surveillance power and obedience in a data-driven economy. Unlike the inmates in a Panopticon, digital service users are not accommodated in a building. This means that they may not be aware of observation or control power. However, the data accumulation logic produces the automatic functioning of surveillance power with technological interventions. As can be seen in nudging, the interventions are relevant but subtle; therefore, individuals rarely notice that they are being watched, and being nudged to change their behaviours when they spend long hours in a digital space that digital service providers offer. This eventually reveals technology-addicted behaviours in daily life.

Together, time and space are key drivers of executing surveillance power that normalises human behaviours. A Panopticon achieved the automatic functioning of surveillance power, and a similar mechanism works in surveillance capitalism because digital service users are required to normalise their behaviours when they spend time in digital space. Yet, the surveillance power in the data accumulation logic may be more influential than in a Panopticon because technology interventions are subtle and well-designed enough for users 
not to sense that they are being observed or hooked. As a result, a modern Panopticon yields technology addictions by consuming users' time and space.

\section{The Basic Assumption of Technology in the Two Realities}

The behavioural-economical-psychoanalytical perspective reveals that a key driver of technology addiction is surveillance power that consumes individuals' time and space. The freedom to use personal time and space is a fundamental right of human beings, and technology is thought to increase the efficiency of time and space. It is certain that technology is a powerful tool to increase enterprises' profits in surveillance capitalism, and Internet service users benefit from these technological services. Yet, there is another new reality, wherein Internet service users are often threatened with behavioural modification without their consent. As can be seen in a modern Panopticon, these two realities of technology reshape surveillance power in the digital age. Given this fact, a critical issue of technology is not caused by technology itself; rather, humans produce a new form of surveillance power in digital spaces by blending technology advancement, the fundamental needs of human behaviours, and the principle of making a profit in capital economy. Thus, a core question here is not how to maximise the benefit of technology or how to mitigate its negative impacts. Rather, we should focus on how to accept two realities to survive and thrive with technology advancement.

There are three primary ways to survive and thrive in the digital age with these two realities. First, we would argue that we should be more aware that technology inevitably brings about both benefits and risks for individuals and societies, and we cannot take only the benefits. In surveillance capitalism, Internet service users are involved in the data accumulation logic to change their behaviours without their awareness, which eventually produces a profit for the service providers. If the users would be more cautious about this data accumulation logic, they may not change their behaviours as the service providers expect. This could avoid the risk that users' behavioural autonomy in digital services is protected, but this would not increase the service providers' profits. This finally may cause a new risk, where service providers cannot ensure their business continuity because of decrease in their profits. Second, we should accept that the complexity of technology-related issues, such as technology-addicted behaviour, is produced by many factors, including a combination of technology, human behavioural patterns, and an economic principle of capitalism. As previously discussed, if we attempt to abolish the negative impacts of technological issues, it will merely give rise to a new economic issue because the addicted use of technology is closely related to the principles of a capitalist economy. Third, we should not be pessimistic about technology's inevitability or complexity. It is true that we simply cannot avoid some of the negative impacts of technology. Yet, we should remember that individuals can take ownership of their time and space, regardless of the technological benefits or risks. That is, basic human rights ensure individuals' freedom to spend their time and space as they please. Because some digital interventions are invisible, we may seldom notice that we consume a lot of time and space in digital technology services. The idea of a modern Panopticon helps us keep in mind that we should more seriously realise that time and space are limited resources. There are important questions we must ask ourselves, including: Who is the owner of one's time and space? What is the purpose of using technology? And what kinds of benefits and risks should individuals accept from technology?

\section{CONCLUSION}

Behavioural science clarified that digital technology services are designed to meet users' fundamental needs, which leads to technology-addicted behaviours, wherein users spend 
excessive time and efforts in online activities. Economic perspectives revealed that technologyaddicted behaviours are embedded in surveillance capitalism, in which user experiences and their outcomes are important resources through which enterprises can make a profit. The underlying mechanism of surveillance capitalism is that surveillance power facilitates individuals' automatic behaviours. A metaphor of surveillance power in psychoanalysis identified a common point between a Panopticon and surveillance capitalism. The automatic functioning of surveillance power occupies individuals' time and space, which, in turn, threatens individuals' sovereignty. There is no doubt that occupying individuals' time and space produces an automatic functioning of surveillance power, which finally shapes individuals' technology-addicted behaviours in the digital era. We would argue that we should spend our daily lives considering the inevitable benefits and risks of technology, the complexity underlying technology-related issues, and the importance of protecting individual sovereignty.

\section{REFERENCES}

Alter, A. 2017. Irresistible: Why we can't stop checking, scrolling, clicking and watching. London: Penguin Books.

Bauman, Z. 2000. Social issues of law and order. British Journal of Criminology

40 (2): 205-221.

Bazarova, N. N., Y. H. Choi, V. Schwanda Sosik, D. Cosley, and J. Whitlock. 2015. Social sharing of emotions on Facebook: Channel differences, satisfaction, and replies (paper presented at the 18th ACM Conference on Computer supported Cooperative Work \& Social Computing, February 2015, 154-164), https://doi.org/10.1145/2675133.2675297.

Block, J. J. 2008. Issues for DSM-V: Internet addiction. American Journal of Psychiatry 165 (3): 306-307.

Burke, M., C. Marlow, and T. Lento. 2010. Social network activity and social well-being (paper presented at the SIGCHI Conference on Human Factors in Computing Systems, April 2010, 1909-1912), https://doi.org/10.1145/1753326.1753613.

Burrow, A. L., and N. Rainone. 2016. How many likes did I get?: Purpose moderates links between positive social media feedback and self-esteem. Journal of Experimental Social Psychology 69: 232-236.

Butler, C. R., A. M. O'Hare, B. R. Kestenbaum, G. G. Sayre, and S. P. Y. Wong. 2021. An introduction to qualitative inquiry. $J$ Am Soc Nephrol 32 (6):1275-1278.

Caluya, G. 2010. The post-panoptic society? Reassessing Foucault in surveillance studies. Social Identities 16 (5): 621-633.

Das, A., M. K. Sharma, P. Thamilselvan, and P. Marimuthu. 2017. Psychological problems: Implication for screening in mental health setting. Indian J Psychol Med 39 (1): 21-27.

Davis, R. A. 2001. A cognitive-behavioral model of pathological Internet use. Computers in Human Behaviour 17 (2): 187-195.

Djurica, D., and K. Figl. 2017. The effect of digital nudging techniques on customers' product choice and attitudes towards e-commerce sites (paper presented at the Twenty-Third Americas Conference on Information Systems, Boston, 2017, 1-5).

Elmer, G. 2012. Panopticon-discipline-control. In Routledge handbook of surveillance studies, eds. Kirstie Ball, Kevin Haggerty, and David Lyon, 28-33. London: Routledge.

Evans, J. St. B. T. 2008. Dual-processing accounts of reasoning, judgment, and social cognition. Annual Review of Psychology 59: 255-278.

Ferraro, G., B. Caci, A. D’Amico, and M. Di Blasi. 2007. Internet addiction disorder: An Italian study. Cyberpsychology \& Behavior 10 (2): 170-175. 
Foucault, M. 1977. Discipline and punishment: The birth of the prison. London: Penguin Books.

Kahneman D., and S. Frederick. 2002. Representativeness revisited: Attribute substitution in intuitive judgement. In Heuristics and biases: The psychology of intuitive judgment, eds. Thomas Gilovich, Dale Griffin, and Daniel Kahneman, 49-81. Cambridge: Cambridge Univ. Press.

Koskela, H. 2003. Cam era: The contemporary urban Panopticon. Surveillance \& Society 1 (3): 292-313.

Kuss, D. J., and M. D. Griffiths. 2017. Social networking sites and addiction: Ten lessons learned. International Journal of Environmental Research and Public Health 14 (3): 311. https://doi.org/10.3390/ijerph14030311.

Lyon, D. 2001. Surveillance society: Monitoring everyday life. Buckingham: Open University Press.

Maddux, J. F., and D. P. A. Desmond. 2000. Addiction or dependence? Addiction 95 (5): 661665.

Mayer-Schönberger, V., and K. Cukier. 2013. Big Data: A revolution that will transform how we live, work, and think. Boston, MA: Houghton Mifflin Harcourt.

Morahan-Martin, J., and P. Schumacher. 2000. Incidence and correlates of pathological Internet use among college students. Computers in Human Behavior 16 (1): 13-29.

Norris, C., and G. Armstrong. 1999. The maximum surveillance society: The rise of CCTV. Oxford: Berg Publishers.

Oh, H. J., E. Ozkaya, and R. LaRose. 2014. How does online social networking enhance life satisfaction?: The relationships among online supportive interaction, affect, perceived social support, sense of community, and life satisfaction. Computers in Human Behavior 30: 69-78.

Poster, M. 1990. The mode of information: Poststructuralism and social context. Cambridge: Polity Press.

Potenza, M. N. 2006. Should addictive disorders include non-substance-related conditions? Addiction 101 (1): 142-151.

Shapira, N. A., T. D. Goldsmith, P. E. Keck, U. M. Khosla, and M. L. McElroy. 2000. Psychiatric features of individuals with problematic Internet use. Journal of Affective Disorders 57 (1-3): 267-272.

Riva, G., B. K. Wiederhold, and P. Cipresso. 2016. Psychology of social media: From technology to identity. In The psychology of social networking: Personal experience in online communities, eds. Giuseppe Riva, Brenda K. Wiederhold, and Pietro Cipresso, 1-11. Poland: De Gruyter Open.

Toma, C. L, and J. T. Hancock. 2013. Self-affirmation underlies facebook use. Personality and Social Psychology Bulletin 39 (3): 321-331.

Turel, O., A. Serenko, and P. Giles. 2011. Integrating technology addiction and use: An empirical investigation of online auction users. MIS Quarterly 35 (4): 1043-1061.

Valkenburg, P. M., J. Peter, and A. P. Schouten. 2006. Friend networking sites and their relationship to adolescents' well-being and social self-esteem. Cyberpsychology \& Behavior, 9 (5): 584-590.

Young, K. S. (1998). Internet addiction: The emergence of a new clinical disorder. Cyberpsychology and Behavior 1 (3): 237-244.

Zuboff, S. 2015. Big other: Surveillance capitalism and the prospects of an information civilization. Journal of Information Technology 30: 75-89.

Zuboff, S. 2019. The age of surveillance capitalism: The fight for a human future at the new frontier of power. London: Profile Books Ltd. 
Zuckerman, A. 2020a. 46 Internet Addiction Statistics: 2020/2021 date, facts \& predictions. 2020a. Compare Camp. https://comparecamp.com/internet-addiction-statistics/ (accessed July 14, 2021).

Zuckerman, A. 2020b. 109 Technology addiction statistics: 2020/2021 data, facts \& insights. 2020b. Compare Camp. https://comparecamp.com/technology-addictionstatistics/\#TOC1 (accessed July 14, 2021).

ERIKA MATSUI

United International Business Schools

Rue Dejoncker 42-46,

1060 Brussels, Belgium

*Corresponding author: erika.matsui@student.uibs.org.

Received: 1 September 2021 / Accepted: 5 November 2021 / Published: 20 November 2021 